\title{
Effects of high-sodium diet on lithogenesis in a rat experimental model of calcium oxalate stones
}

\author{
Yang Hong ${ }^{1,2}$, Zaixian Zhang ${ }^{1,2}$, Haiyun $\mathrm{Ye}^{1,2}$, Lizhe $\mathrm{An}^{1,2}$, Xiaobo Huang ${ }^{1,2}$, Qingquan Xu ${ }^{1,2}$ \\ ${ }^{1}$ Urology and lithotripsy center, Peking University People's Hospital, Beijing, China; ${ }^{2}$ The institute of applied lithotripsy technology, Peking \\ University, Beijing, China \\ Contributions: (I) Conception and design: Y Hong, Z Zhang, Q Xu, X Huang; (II) Administrative support: H Ye, L An; (III) Provision of study \\ materials or patients: Y Hong, L An; (IV) Collection and assembly of data: Z Zhang, H Ye; (V) Data analysis and interpretation: Y Hong, Z Zhang, \\ L An; (VI) Manuscript writing: All authors; (VII) Final approval of manuscript: All authors. \\ Correspondence to: Xiaobo Huang; Qingquan Xu. 133\#, Fuchengmen Inner Street, Beijing 100034, China. Email: huang6299@sina.com; \\ xuqingquan@bjmu.edu.cn.
}

Background: This study aimed to investigate the effects of a high- and low-sodium diets on lithogenesis in a rat experimental model of calcium oxalate stones.

Methods: Twenty male Wistar rats were randomly divided into four groups; group A: 4\% $\mathrm{NaCl}+1 \%$ ethylene glycol (EG); group B: $8 \% \mathrm{NaCl}+1 \% \mathrm{EG}$; group C: $8 \% \mathrm{NaCl}+$ normal drinking-water; group D: $1 \% \mathrm{EG}$ + normal diet. All rats were sacrificed 4 weeks later, and blood samples were collected from the heart. The kidneys were collected for Von Kossa staining to evaluate the formation of calcium-containing crystals. The last 24-h urine samples were also gathered for metabolic analysis.

Results: Von Kossa staining demonstrated that the rats in both group A and group B had significantly more renal calcium crystals than those in group D. However, 24-h urinary volume increased significantly $(142.26 \pm 20.91 \mathrm{~mL})$ in group B compared with group A $(100.52 \pm 28.23 \mathrm{~mL})$, group C $(107.36 \pm 14.24 \mathrm{~mL})$, group $\mathrm{D}(40.79 \pm 8.71 \mathrm{~mL})(\mathrm{P}=0.004,0.012$, and 0.000 respectively). Level of urine sodium $(\mathrm{Na})$, potassium $(\mathrm{K})$, chlorine $(\mathrm{Cl})$, and calcium $(\mathrm{Ca})$, urea nitrogen were significantly higher in group B compared with group D. The urine phosphorus, oxalate, and creatinine levels; urine specific gravity; and urine $\mathrm{PH}$ were similar between group B and group D. The level of serum sodium was higher in group B $(151.26 \pm 4.06 \mathrm{mmol} / \mathrm{L})$ compared with group D $(145.56 \pm 1.12 \mathrm{mmol} / \mathrm{L})(\mathrm{P}=0.002)$.

Conclusions: A high sodium intake might increase the risk of lithogenesis in susceptible individuals (given by EG) or in individuals with water restriction.

Keywords: Animal model; high-sodium diet; kidney calculi; metabolic

Submitted Aug 31, 2020. Accepted for publication Dec 02, 2020.

doi: $10.21037 /$ tau-20-1226

View this article at: http://dx.doi.org/10.21037/tau-20-1226

\section{Introduction}

Urolithiasis is a common disorder with a continuous increase in incidence. Recent studies showed an obvious increase in the prevalence of urolithiasis in the United States, Germany, Italy, and Japan. In the United States, it was estimated that $12 \%$ of men and $6 \%$ of women would develop kidney stones in a certain period during their whole life (1). Besides, urolithiasis has a high recurrence rate, with recurrence rate
$30-50 \%$ after 5 years and almost $70 \%$ after 10 years (2).

In the last two decades, the minimally invasive techniques of stone treatment, including ureteroscopy, retrograde intrarenal surgery, and percutaneous nephrolithotomy, have made great progress (3). However, the problems of recurrence and regrowth are still remaining unresolved because the precise pathogenic steps in stone formation in humans remain elusive.

Nephrolithiasis is associated with individual and 
Table 1 Groups and diets

\begin{tabular}{ll}
\hline Groups & Diets \\
\hline A & $1 \%$ ethylene glycol in water $+4 \% \mathrm{NaCl}$ diet \\
B & $1 \%$ ethylene glycol in water $+8 \% \mathrm{NaCl}$ diet \\
C & normal water $+8 \% \mathrm{NaCl}$ diet \\
D & $1 \%$ ethylene glycol in water + standard diet \\
\hline
\end{tabular}

environmental factors. Individual factors include metabolic disturbance, inheritance, urinary tract infection, and obstruction. Environmental factors include climate, dietary habits, drugs, and career (4). Most of these factors are difficult to control; however, dietary adjustment is easier for patients.

Various dietary measures have been evaluated for the effect on urinary stone formation. Low animal protein intake, low sodium consumption, increased fluid intake, and normal calcium diet showed protective effects $(5,6)$. However, the independent relationship between sodium intake and nephrolithiasis is still controversial (7). Sakhaee et al. evaluated high-sodium diet (basal diet plus $250 \mathrm{mmol}$ sodium chloride per day) as the risk for kidney stone formation (8). They found that a high-sodium intake not only increased calcium excretion but also increased urinary $\mathrm{pH}$ and decreased citrate excretion (8). Citrate has been verified as a protective factor for urinary stone formation (9). Another clinical study found that dietary sodium supplementation resulted in an increased voided urine volume by voluntary increased fluid intake, which decreased the supersaturation ratio for calcium oxalate stones in patients with a history of hypocitraturic calcium oxalate nephrolithiasis. It may be inappropriate to restrict sodium intake in patients with hypocitraturia and recurrent urinary stones (10).

No randomized controlled trial evaluated the role of dietary sodium intake in kidney stone formation. This study evaluated the independent relationship between different levels of dietary sodium intake and the risk of kidney stone formation, using a rat model of calcium oxalate stones. We present the following article in accordance with the ARRIVE reporting checklist (available at http://dx.doi. org/10.21037/tau-20-1226).

\section{Methods}

\section{Animals}

Male Wistar rats (8-10 weeks of age) were purchased from
Vital River (a Charles River joint venture company in China). The animals were housed in an air-conditioned room maintained at $20-26{ }^{\circ} \mathrm{C}$ and $40-70 \%$ relative humidity. The body weight was measured, and a 12-h light and dark cycle was automatically maintained. The animals were provided with food and water ad libitum. Experiments were performed under a project license (NO.: 2015-18) granted by ethics board of Peking University People's Hospital, in compliance with the "Guide to the Care and Use of Experimental Animals".

\section{Preparation of different diets}

Two kinds of high-sodium pellet diets were purchased from Vital River Company. The sodium chloride content was $4 \%$ and $8 \%$, respectively, which was $0.3 \%$ in the standard pellet diet. Ethylene glycol (EG) water (1\%) was purchased from Sinopharm Chemical Reagent Beijing Co., Ltd. as the lithogenic agent.

\section{Experimental design and protocol}

A total number of 20 animals were randomly divided into the following 4 groups (A, B, C, and D), comprising 5 animals per group (Table 1): group A: $4 \% \mathrm{NaCl}+1 \% \mathrm{EG}$; group B: $8 \% \mathrm{NaCl}+1 \% \mathrm{EG}$; group C: $8 \% \mathrm{NaCl}+$ normal drinking water; group D: $1 \% \mathrm{EG}+$ normal diet. The rats were fed for 4 weeks. The rats from each group were placed individually in metabolic cages for $24 \mathrm{~h}$ for recording urine output.

\section{Urine parameters}

One day before sacrificed, 24-h urine samples were collected from rats. The urine samples were analyzed for $\mathrm{pH}$, specific gravity, and levels of urea nitrogen, chlorine, calcium, creatinine, phosphorus, potassium, sodium, and oxalate.

\section{Serum parameters}

All rats were sacrificed by intraperitoneal injection of excessive $2 \%$ pentobarbital. The serum was collected by cardiac puncture. The serum was separated by centrifugation at $1,500 \mathrm{rpm}$ at $4{ }^{\circ} \mathrm{C}$ for $15 \mathrm{~min}$ for biochemical and electrolyte analyses.

\section{Histopathology}

Both kidneys of rats were dissected, and the kidney weight 
Table 2 Weight of rat body and kidneys, and positive rate of Von Kossa staining (means \pm SEM)

\begin{tabular}{lcccc}
\hline Parameters & $\mathrm{A}(4 \% \mathrm{NaCl}+1 \% \mathrm{EG})$ & $\mathrm{B}(8 \% \mathrm{Nacl}+1 \% \mathrm{EG})$ & $\mathrm{C}(8 \% \mathrm{NaCl})$ & $\mathrm{D}(1 \% \mathrm{EG})$ \\
\hline Body weight $(\mathrm{g})$ & $391.40 \pm 30.05$ & $359.00 \pm 56.27$ & $404.00 \pm 23.19$ & $391.60 \pm 30.13$ \\
Kidney weight $(\mathrm{g})$ & $6.60 \pm 1.34$ & $6.40 \pm 1.52$ & $3.40 \pm 0.55$ & $4.60 \pm 0.89^{\star \star}$ \\
Von Kossa positive rate (\%) & $5.02 \pm 1.28^{\star}$ & $15.36 \pm 2.38^{\star}$ & 0 & $2.10 \pm 1.39^{\star}$ \\
\hline
\end{tabular}

${ }^{*}$, indicates significant difference from the other three groups $(P<0.05) ;{ }^{* *}$, indicates significant difference from group $D$ and group $A / B$ $(P<0.05)$. SEM, standard error of the mean; $E G$, ethylene glycol.
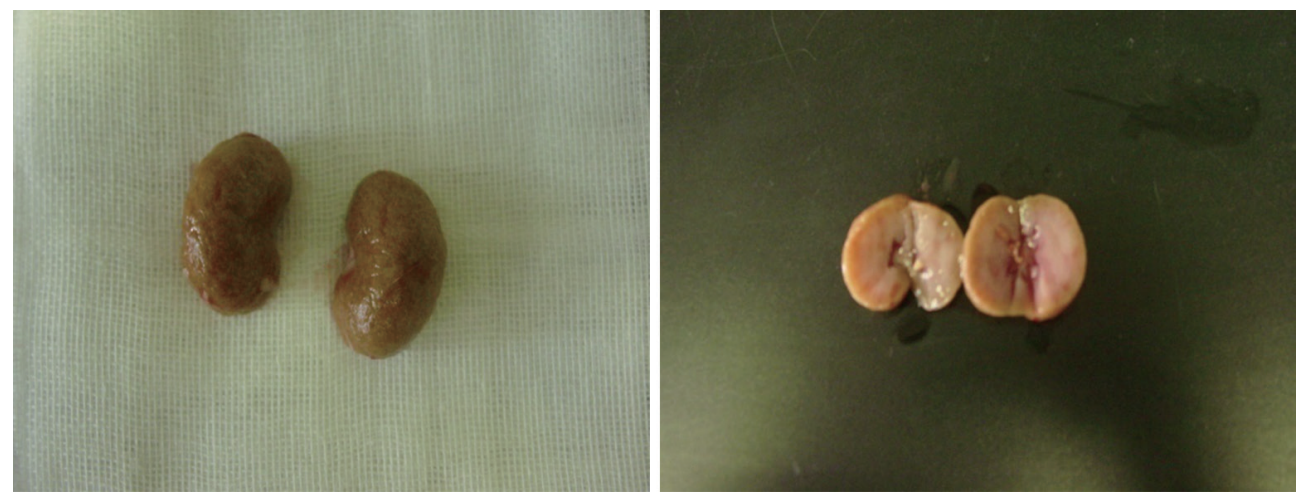

Figure 1 Gross specimen of kidney of group B. Stone particles could be find on the surface and section of kidney.

was determined at sacrifice. One kidney from each rat was placed in $10 \%$ formalin solution for $3-24 \mathrm{~h}$. The organ specimen was subjected to dehydration with xylene $(2 \mathrm{~h}$ each) and alcohol of strength 70\%, 80\%, 90\%, and $95 \%$ for $24 \mathrm{~h}$, and $100 \%$, for $2 \mathrm{~h}$. The infiltration and impregnation were carried out by treatment with paraffin wax for $2 \mathrm{~h}$. The specimens were cut into sections of 4- to 7- $\mu$ m-thick and stained by the Von Kossa method. The $\mathrm{CaOx}$ deposition was determined.

\section{Statistical analysis}

For analytical method validation, all statistical analyses were performed in SPSS (v.13.0, IBM, USA). The results were expressed as mean \pm standard error of the mean. The groups were compared by analysis of variance. The results were considered significant at $\mathrm{P} \leq 0.05$.

\section{Results}

All rats were sacrificed at the end of the study. No statistically significant difference in body weight was found between the groups. The means of kidney weight means were significantly higher in group A and group B compared with group $\mathrm{D}(\mathrm{P}=0.014$ and 0.024 , respectively). No significant difference was found between group A and group $\mathrm{B}(\mathrm{P}=0.785)$. Von Kossa staining of histopathology revealed more calcium crystal deposition in group A $(5.02 \% \pm 1.28 \%)$ and group B $(15.36 \% \pm 2.38 \%)$ compared with group D $(2.10 \% \pm 1.39 \%)(\mathrm{P}<0.05)$. Most of the crystals were seen in the tubule and glomerulus. Sediment particles were observed on the surface and in the section of the kidney (Table 2 and Figures 1,2).

\section{Urine parameters}

The urinary output in group $\mathrm{B}(8 \% \mathrm{NaCl}+1 \% \mathrm{EG})$ was $(142.26 \pm 20.91 \mathrm{~mL} / \mathrm{d})$, significantly higher than that in group $\mathrm{A}(4 \% \mathrm{NaCl}+1 \% \mathrm{EG})$, group $\mathrm{C}(8 \% \mathrm{NaCl})$, and group $\mathrm{D}(1 \% \mathrm{EG})(\mathrm{P}=0.004,0.012$ and 0.000, respectively). However, no significant difference was observed between group $\mathrm{A}(4 \% \mathrm{NaCl}+1 \% \mathrm{EG})$ and group $\mathrm{C}(8 \% \mathrm{NaCl})$ $(\mathrm{P}=0.586)$. The urinary sodium, potassium, calcium, chlorine and urea nitrogen levels were significantly different across the groups $(\mathrm{P}<0.05)$; these levels increased in group $\mathrm{B}(8 \% \mathrm{NaCl}+1 \% \mathrm{EG})$ compared with group D (1\% EG). 

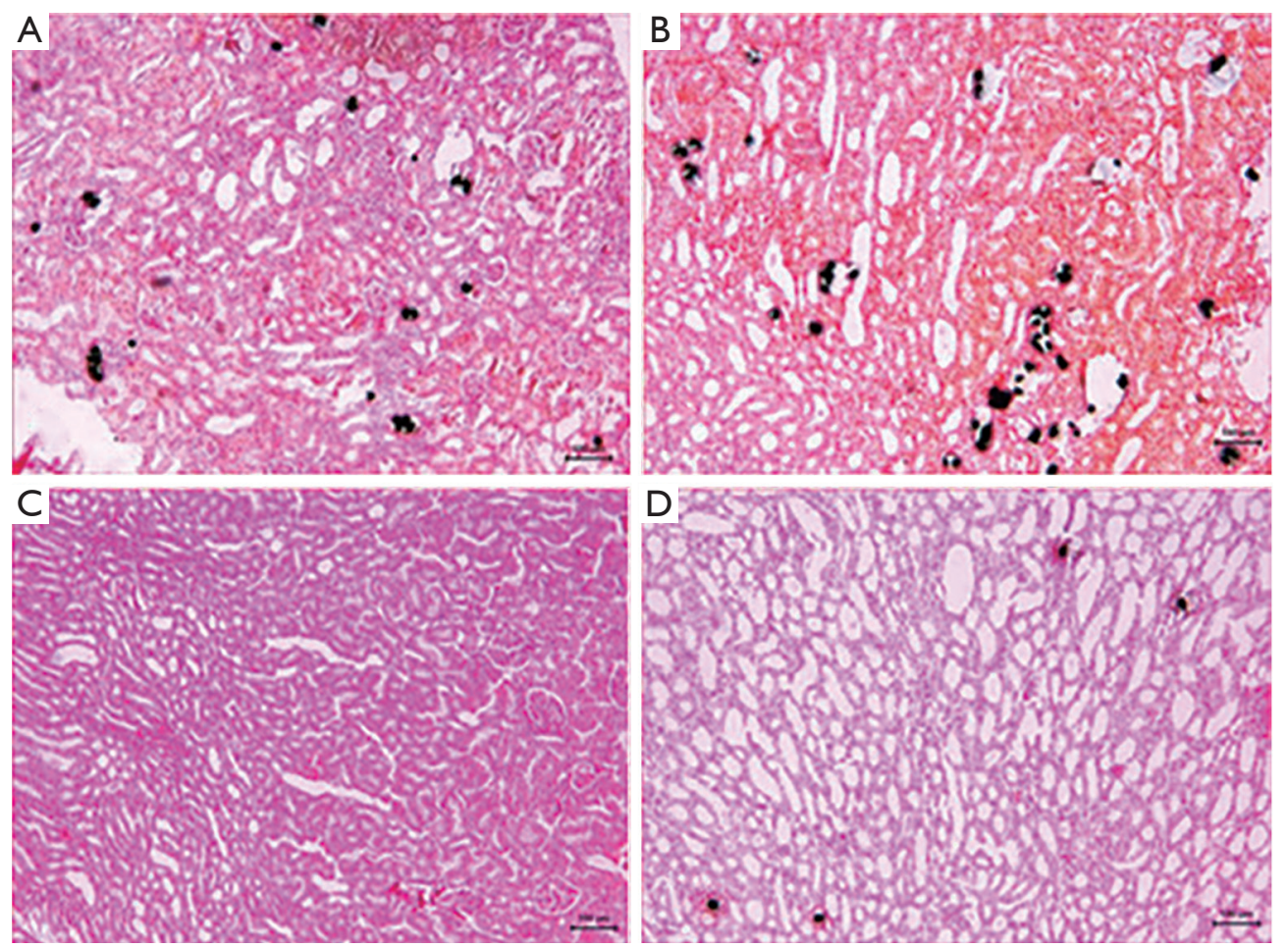

Figure 2 Light microscopic architecture and calcium oxalate deposits in the kidney section. (A) Group A: medium deposition of crystals; (B) group B: maximum deposition of crystals; (C) group C: does not showed deposition of crystals; (D) group D: showed minimum deposition of crystals. Von Kossa staining; scale bar: $100 \mu \mathrm{m}$.

No significant difference was found in urinary phosphorus, oxalate, and creatinine levels; specific gravity; and $\mathrm{pH}$ across the groups (Table 3).

\section{Serum parameters}

The concentrations of sodium and carbon dioxide in the serum were significantly different significantly across the groups $(\mathrm{P}=0.005$ and 0.042 respectively). The serum sodium level increased in group B $(151.26 \pm 4.06)$ compared with group $C(146.20 \pm 2.21)$ and $D(145.56 \pm 1.12)(P=0.005$ and 0.002 , respectively). No significant difference in other serum parameters was detected across the groups (Table 4).

\section{Discussion}

A high-sodium diet has traditionally been considered a risk factor for stone formation. Many urologists have recommended limiting dietary sodium chloride intake for patients with stone formation. However, a positive effect of oral sodium supplementation with regard to the risk of nephrolithiasis was also reported by some studies, making the relationship between sodium intake and nephrolithiasis controversial (10). Many similarities exist between experimental lithogenesis induced in rats and humans (11). The present study investigated the independent relationship between sodium diet and changes in urine and serum levels of analytes in a rat model of calcium oxalate nephrolithiasis. The results of the present study demonstrated that with the increased sodium intake, the model had significantly increased urine output and urinary sodium, potassium, chloride, calcium, and nitrogen excretion, with no change in urinary oxalate level, specific gravity, and $\mathrm{pH}$. The serum parameters revealed that the sodium concentration significantly increased when the rats were fed a highsodium diet and EG water, compared with rats fed each diet separately. Furthermore, a high sodium intake promoted the deposition of calcium crystals in the tubule and glomerulus, thus contributing to stone formation. These findings indicated that a high-sodium intake was an independent risk factor for stone formation.

Clinical and metabolic studies suggested that increasing 
Table 3 Urine analytes (mean \pm SD)

\begin{tabular}{lcccc}
\hline Urine analytes & A & B & C & D \\
\hline Total vol $(\mathrm{mL} / 24 \mathrm{~h})$ & $100.53 \pm 28.23$ & $142.26 \pm 20.91$ & $107.36 \pm 14.24$ & $40.79 \pm 8.71$ \\
Phosphorus $(\mu \mathrm{mol} / 24 \mathrm{~h})$ & $355.51 \pm 274.69$ & $593.69 \pm 451.95$ & $874.95 \pm 873.65$ & $583.90 \pm 173.21$ \\
Sodium $(\mathrm{mmol} / 24 \mathrm{~h})$ & $11.30 \pm 6.10$ & $24.59 \pm 13.11$ & $31.03 \pm 9.43$ & $3.94 \pm 1.11$ \\
Potassium $(\mathrm{mmol} / 24 \mathrm{~h})$ & $3.45 \pm 1.15$ & $5.88 \pm 1.50$ & $3.37 \pm 0.83$ & $4.03 \pm 1.26$ \\
Chlorine $(\mathrm{mmol} / 24 \mathrm{~h})$ & $10.99 \pm 5.62$ & $20.11 \pm 7.20$ & $14.18 \pm 13.04$ & $4.39 \pm 2.08$ \\
Nitrogen $(\mathrm{mmol} / 24 \mathrm{~h})$ & $5.28 \pm 3.29$ & $8.63 \pm 4.50$ & $3.19 \pm 1.75$ & 0.001 \\
Creatinine $(\mathrm{mmol} / 24 \mathrm{~h})$ & $86.09 \pm 24.84$ & $135.80 \pm 53.91$ & $155.02 \pm 65.02$ & 0.015 \\
Calcium $(\mu \mathrm{mol} / 24 \mathrm{~h})$ & $158.75 \pm 52.59$ & $296.05 \pm 59.51$ & $651.64 \pm 261.40$ & $89.04 \pm 0.18$ \\
Oxalate $(\mu \mathrm{mol} / 24 \mathrm{~h})$ & $3.11 \pm 1.72$ & $2.86 \pm 1.93$ & $1.59 \pm 0.13$ & 0.003 \\
Specific gravity $(\mathrm{g} / \mathrm{mL})$ & $1.010 \pm 0.002$ & $1.014 \pm 0.009$ & $1.010 \pm 0.000$ & $1.86 \pm 1.48$ \\
PH & $8.00 \pm 1.22$ & $8.60 \pm 0.55$ & $9.00 \pm 0.000$ & 0.052 \\
\hline
\end{tabular}

SD, standard deviation.

Table 4 Serum analytes $($ mean \pm SD)

\begin{tabular}{lcccc}
\hline Serum analytes & A & B & C & D \\
\hline Phosphorus (mmol/L) & $2.89 \pm 0.26$ & $2.62 \pm 0.41$ & $2.62 \pm 1.39$ & $2.96 \pm 0.28$ \\
Sodium (mmol/L) & $145.64 \pm 1.23$ & $151.26 \pm 4.06$ & $146.20 \pm 2.21$ & $145.56 \pm 1.12$ \\
$\mathrm{CO}_{2}(\mathrm{mmol} / \mathrm{L})$ & $23.92 \pm 2.53$ & $26.28 \pm 1.46$ & $28.26 \pm 2.71$ & $26.48 \pm 1.60$ \\
Potassium (mmol/L) & $5.30 \pm 0.46$ & $4.95 \pm 1.02$ & $5.24 \pm 0.72$ & $5.58 \pm 0.74$ \\
\hline
\end{tabular}

SD, standard deviation.

the intake of water reduced the risk of urinary stone formation $(6,12)$. A decrease in water intake increased the urine $\mathrm{pH}$, specific gravity, and saturation, contributing to the nucleation of calcium oxalate crystals (13). In the present study, although the urine output was increased as a result of a high-sodium diet, its protective effect on stone formation was not observed; instead, it led to the increased deposition of calcium crystals. It was presumed that a high-sodium diet might result in thirst in rats, leading to increased water intake with EG. Increased urine output diluted the inhibitory factors (citrate, magnesium, etc.) for stone formation (14). However, the levels of citrate and magnesium were not detected in this study. On the contrary, although urinary sodium and calcium levels were significantly higher in highsodium intake groups, no difference in urine specific gravity and $\mathrm{pH}$ were observed. Perhaps increased urine output did not change urine saturation and hence did not reduce the stone formation (15).

Studies showed that a high-sodium diet was related to more urinary calcium excretion in patients with calcium oxalate stones, compared with normal individuals $(16,17)$. Sakhaee et al. examined 14 normal participants and found increased urinary calcium in $44 \%$ and decreased urinary citrate in $20 \%$ of patients with a high-sodium intake for 10 days (8). No change in urine output was detected with a restriction of fluid intake. Also, the analysis of urine parameters revealed that the urinary saturation of calcium phosphate and monosodium increased, but the saturation of calcium oxalate remained unchanged. In the present study, the urine output and calcium excretion were significantly increased with a high-sodium diet without the restriction of fluid intake. Increased urinary oxalate level and specific gravity and decreased urine $\mathrm{pH}$ were observed, but the difference was not statistically significant.

The serum parameters revealed that the level of sodium significantly increased when the rats were fed a highsodium diet and EG water, while no difference was found when the rats were fed each diet separately. This finding 
indicated some interactive effects between serum sodium level and stone formation (18). Sodium and calcium were transported together in renal tubules. A high sodium intake decreased renal tubule reabsorption of calcium, resulting in increases in urinary calcium and thus promoting stone formation (19). Meanwhile, stone formation might decrease the capacity of sodium excretion and induce an increase in the serum sodium level. Further studies should be conducted to understand the exact interaction between serum sodium level and stone formation (20).

This study had several limitations. The fluid intake was not restricted, and the rats drank randomly. The high-sodium diet led to thirst and hence increased the intake of water and EG. Thus, efforts are underway to confirm the role of a high-sodium diet and an increased EG intake in promoting the deposition of calcium crystals. The urine output was significantly more in group B $(1 \% \mathrm{EG}$ in water $+8 \% \mathrm{NaCl}$ diet) compared with other groups. Also, the output in group $\mathrm{C}$ (normal water $+8 \% \mathrm{NaCl}$ diet) was more than group $\mathrm{A}(1 \% \mathrm{EG}$ in water $+4 \% \mathrm{NaCl}$ diet) and group $\mathrm{D}(1 \%$ $\mathrm{EG}$ in water + standard diet), but no significant difference was observed compared with group A. Perhaps EG also increased the excretion of urine besides promoting stone formation. The urine output of rats fed a normal diet should have been used as a control.

\section{Conclusions}

A high sodium intake may increase the risk of lithogenesis in susceptible individuals (given by EG) or in individuals with water restriction.

\section{Acknowledgments}

The authors would like to thank all the reviewers who participated in the review and MJEditor (www.mjeditor. com) for its linguistic assistance during the preparation of this manuscript.

Funding: None.

\section{Footnote}

Reporting Checklist: The authors have completed the ARRIVE reporting checklist. Available at http://dx.doi. org/10.21037/tau-20-1226

Data Sharing Statement: Available at http://dx.doi. org/10.21037/tau-20-1226
Conflicts of Interest: All authors have completed the ICMJE uniform disclosure form (available at http://dx.doi. org/10.21037/tau-20-1226). The authors have no conflicts of interest to declare.

Ethical Statement: The authors are accountable for all aspects of the work in ensuring that questions related to the accuracy or integrity of any part of the work are appropriately investigated and resolved. Experiments were performed under a project license (NO.: 2015-18) granted by ethics board of Peking University People's Hospital, in compliance with the "Guide to the Care and Use of Experimental Animals".

Open Access Statement: This is an Open Access article distributed in accordance with the Creative Commons Attribution-NonCommercial-NoDerivs 4.0 International License (CC BY-NC-ND 4.0), which permits the noncommercial replication and distribution of the article with the strict proviso that no changes or edits are made and the original work is properly cited (including links to both the formal publication through the relevant DOI and the license). See: https://creativecommons.org/licenses/by-nc-nd/4.0/.

\section{References}

1. Hesse A, Brandle E, Wilbert D, et al. Study on the prevalence and incidence of urolithiasis in Germany comparing the years 1979 vs. 2000. Eur Urol 2003;44:709-13.

2. Park S. Medical management of urinary stone disease. Expert Opin Pharmacother 2007;8:1117-25.

3. Segura JW, Preminger GM, Assimos DG, et al. Nephrolithiasis Clinical Guidelines Panel summary report on the management of staghorn calculi. The American Urological Association Nephrolithiasis Clinical Guidelines Panel. J Urol 1994;151:1648-51.

4. Moriyama MT. Diet therapy and life guidance to prevent calcium stones. Clin Calcium 2011;21:1522-9.

5. Kang HW, Seo SP, Kim WT, et al. Hypertriglyceridemia is associated with increased risk for stone recurrence in patients with urolithiasis. Urology 2014;84:766-71.

6. Curhan GC, Willett WC, Knight EL, et al. Dietary factors and the risk of incident kidney stones in younger women: Nurses' Health Study II. Arch Intern Med 2004;164:885-91.

7. Damasio PC, Amaro CR, Padovani CR, et al. Influence of clinical therapy and nutritional counseling on the 
recurrence of urolithiasis. Acta Cir Bras 2014;29:400-4.

8. Sakhaee K, Harvey JA, Padalino PK, et al. The potential role of salt abuse on the risk for kidney stone formation. J Urol 1993;150:310-2.

9. Pak CY. Medical management of urinary stone disease. Nephron Clin Pract 2004;98:c49-53.

10. Stoller ML, Chi T, Eisner BH, et al. Changes in urinary stone risk factors in hypocitraturic calcium oxalate stone formers treated with dietary sodium supplementation. J Urol 2009;181:1140-4.

11. Khan SR. Animal models of kidney stone formation: an analysis. World J Urol 1997;15:236-43.

12. Taylor EN, Stampfer MJ, Curhan GC. Dietary factors and the risk of incident kidney stones in men: new insights after 14 years of follow-up. J Am Soc Nephrol 2004;15:3225-32.

13. Borghi L, Meschi T, Amato F, et al. Urinary volume, water and recurrences in idiopathic calcium nephrolithiasis: a 5-year randomized prospective study. J Urol 1996;155:839-43.

14. Kato Y, Yamaguchi S, Yachiku S, et al. Changes in urinary

Cite this article as: Hong Y, Zhang Z, Ye H, An L, Huang $\mathrm{X}, \mathrm{Xu} \mathrm{Q}$. Effects of high-sodium diet on lithogenesis in a rat experimental model of calcium oxalate stones. Transl Androl Urol 2021;10(2):636-642. doi: 10.21037/tau-20-1226 parameters after oral administration of potassium-sodium citrate and magnesium oxide to prevent urolithiasis. Urology 2004;63:7-11; discussion 11-2.

15. Siener R, Hesse A. Recent advances in nutritional research on urolithiasis. World J Urol 2005;23:304-8.

16. Aruga S, Honma Y. Renal calcium excretion and urolithiasis. Clin Calcium 2011;21:1465-72.

17. Timio F, Kerry SM, Anson KM, et al. Calcium urolithiasis, blood pressure and salt intake. Blood Press 2003;12:122-7.

18. Xu QQ, Huang XB, Ma K, et al. Analysis of serum electrolytes in urolithiasis patients. Beijing Da Xue Xue Bao 2010;42:451-53.

19. Mochizuki M, Morikawa M, Yogo T, et al. The distribution of several elements in cat urine and the relation between the content of elements and urolithiasis. Biol Trace Elem Res 2011;143:913-22.

20. Agarwal MM, Singh SK, Mavuduru R, et al. Preventive fluid and dietary therapy for urolithiasis: An appraisal of strength, controversies and lacunae of current literature. Indian J Urol 2011;27:310-9. 